\title{
The genome sequence of the commercially cultivated mushroom Agrocybe aegerita reveals a conserved repertoire of fruiting- related genes and a versatile suite of biopolymer-degrading enzymes
}

Deepak K. Gupta 1,3,5, Martin Rühl 4,5,7, Bagdevi Mishra 1,3,5, Vanessa Kleofas ${ }^{4,5}$, Martin Hofrichter ${ }^{6}$, Robert Herzog ${ }^{2,3,5}$, Marek J. Pecyna ${ }^{8}$, Rahul Sharma ${ }^{1,3,5}$, Harald Kellner ${ }^{6}$, Florian Hennicke ${ }^{2,3,5,9^{*}}$ and Marco Thines ${ }^{1,3,5^{*}}$

\begin{abstract}
Background: Agrocybe aegerita is an agaricomycete fungus with typical mushroom features, which is commercially cultivated for its culinary use. In nature, it is a saprotrophic or facultative pathogenic fungus causing a white-rot of hardwood in forests of warm and mild climate. The ease of cultivation and fructification on solidified media as well as its archetypal mushroom fruit body morphology render A. aegerita a well-suited model for investigating mushroom developmental biology.

Results: Here, the genome of the species is reported and analysed with respect to carbohydrate active genes and genes known to play a role during fruit body formation. In terms of fruit body development, our analyses revealed a conserved repertoire of fruiting-related genes, which corresponds well to the archetypal fruit body morphology of this mushroom. For some genes involved in fruit body formation, paralogisation was observed, but not all fruit body maturation-associated genes known from other agaricomycetes seem to be conserved in the genome sequence of $A$. aegerita. In terms of lytic enzymes, our analyses suggest a versatile arsenal of biopolymer-degrading enzymes that likely account for the flexible life style of this species. Regarding the amount of genes encoding CAZymes relevant for lignin degradation, A. aegerita shows more similarity to white-rot fungi than to litter decomposers, including 18 genes coding for unspecific peroxygenases and three dye-decolourising peroxidase genes expanding its lignocellulolytic machinery.

Conclusions: The genome resource will be useful for developing strategies towards genetic manipulation of $A$. aegerita, which will subsequently allow functional genetics approaches to elucidate fundamentals of fruiting and vegetative growth including lignocellulolysis.
\end{abstract}

Keywords: Agaricales, Basidiomycetes, Carbohydrate active enzymes, Comparative genomics, Developmental biology, Fruit body, Mushroom, White-rot

\footnotetext{
* Correspondence: florian.hennicke@senckenberg.de; m.thines@thines-lab.eu Deepak Gupta, Martin Rühl and Florian Hennicke are major contributors of this study.

${ }^{2} J$ unior Research Group Genetics and Genomics of Fungi, Senckenberg Gesellschaft für Naturforschung, Frankfurt a. M., Germany

${ }^{1}$ Senckenberg Biodiversity and Climate Research Centre (BiK-F), Frankfurt a.

M., Germany

Full list of author information is available at the end of the article
} 


\section{Background}

The Black Poplar or Sword-belt Mushroom, Agrocybe aegerita, is a representative of the Agaricales [1], to which also the button mushroom (Agaricus bisporus) belongs. Causing a white-rot, $A$. aegerita is a woodinhabiting agaric primarily degrading dead wood of deciduous trees, especially poplar and willow [2-4]. However, it has also been described as a pathogen in declining individuals of these species, as well as in some other tree species including elm, maple and oak [4]. Although $A$. aegerita sensu lato has been reported from all continents except Antarctica [4], it seems to prefer warm or mild temperate climates as it is commonly found in Southern Europe [3, 5, 6], the south-eastern United States, as well as similar climatic zones in Asia [7]. Agrocybe aegerita sensu lato is a commercially grown choice edible mushroom [8-10] and is reportedly used as a medicinal fungus, especially in Asia [11].

Alongside the model mushrooms Coprinopsis cinerea and Schizophyllum commune, A. aegerita has also been investigated to study the fundamentals of agaricomycete fruit body (mushroom) formation [5, 12-28]. Apart from the normal dikaryotic fruit body formation, A. aegerita is also capable of monokaryotic fruiting. This phenomenon has been analysed by classical microbiology and genetics approaches, revealing a wide spectrum of monokaryotic fruiting types, including some that complete the development until basidiospore formation [5, 12, 14, 27]. Monokaryons offer advantages for the analysis of genes involved in fruit body formation, but monokaryotic fruiter strains are also of potential interest for edible mushroom production, as they usually produce only low amounts of spores, a desired trait in mushroom farming [27, 29, 30].

To produce culinary fruit bodies, $A$. aegerita is cultivated on various lignocellulosic substrates. In most cases straw is used as a basis, which can be supplemented with sidestream products of agriculture and food production, e.g. black tea pomace, carrot mesh, citrus pellets, cocoa shells, bran powder, sawdust, cotton waste, orange peels and grape stalks $[9,10,31-33]$. Biomass production by A. aegerita was evaluated not only for human nutrition [10] and medical applications [34, 35], but also for recycling of abundant agro-industrial residues like olive mill wastewater [36] or poultry litter [33]. The capability of A. aegerita to chemically modify and degrade lignin is due to several peroxidases, $\mathrm{H}_{2} \mathrm{O}_{2}$-generating enzymes and laccases. So far, none of the typical lignin degrading class II peroxidases, i.e. manganese peroxidases (MnPs), lignin peroxidases, or versatile peroxidases have been found to be expressed during growth on lignocellulose or in liquid media [11]. However, A. aegerita produces an unspecific peroxygenase (UPO) belonging to the heme-thiolate peroxidase superfamily, which is capable of catalysing peroxidation (one-electron oxidations) and peroxygenation (oxyfunctionalisations) of a wide array of substrates [37, 38]. The actual role of this enzyme in lignocellulose disintegration is still unknown, though it has been shown to cleave recalcitrant dimeric lignin moieties [39]. Lignin-modifying laccase activity was detected both in liquid media and in lignocellulose-based solid-state cultures [33, 40]. Even though a transcriptomics study revealed some genes coding for cellulolytic enzymes [11], a comprehensive genomic analysis of $A$. aegerita and its lignocellulose-degrading enzymes is still missing.

Thus, it was the aim of the present study to sequence and annotate the genome of the dikaryotic strain $A$. aegerita AAE-3 and of a pair of mating-compatible monokaryotic sibling strains derived from it, the strains A. aegerita AAE-3-13 and $A$. aegerita AAE-3-32, previously characterised by Herzog et al. [27]. This strain pair represents the extremes of the monokaryotic fruiting spectrum ranging from no production of fruiting stages ('mycelium type') in $A$. aegerita AAE-3-13 to the production of monokaryotic low-sporulation fruit bodies ('fruiter type') in A. aegerita AAE-3-32.

\section{Methods}

Strains, culture conditions and isolation of nucleic acids

Strain cultivation and maintenance as well as fruit body induction of $A$. aegerita AAE-3 was done as previously described [27]. Genomic DNA of $A$. aegerita AAE-3 was extracted using $A$. aegerita AAE-3 cultures grown in liquid YMG medium (4 g yeast extract, $10 \mathrm{~g}$ malt extract, and $4 \mathrm{~g}$ glucose in $1 \mathrm{~L}$ of $\mathrm{dd}_{2} \mathrm{O}$ ) for 8 days at $24{ }^{\circ} \mathrm{C}$ in darkness at $150 \mathrm{rpm}$ on an Orbitron shaker (Infors HT, Bottmingen, Switzerland). Fungal mycelium was separated from the culture medium and rinsed with sterile water. The mycelium was ground in liquid nitrogen using a mortar and pestle. DNA was isolated from the resulting powder using the method of McKinney et al. [41] with some modifications. First, the powder was distributed to several $2 \mathrm{~mL}$ reaction vials. For this, a tip of a spatula of the ground sample was re-suspended in $200 \mu \mathrm{L}$ extraction buffer (50 mM Tris pH 8.0, $200 \mathrm{mM}$ $\mathrm{NaCl}, 0.2 \mathrm{mM}$ EDTA, $0.5 \% \mathrm{SDS}, 0.1 \mathrm{mg} / \mathrm{mL}$ Proteinase $\mathrm{K}$ ) and incubated for $30 \mathrm{~min}$ at $37{ }^{\circ} \mathrm{C}$. An incubation step of $15 \mathrm{~min}$ followed after adding $10 \mu \mathrm{L}$ RNAse. Afterwards, $200 \mu \mathrm{L}$ of a phenol:chloroform:isoamyl alcohol mixture (25:24:1) was added and samples were gently mixed. Phases were separated by centrifugation and the aqueous layer was transferred to a new $2 \mathrm{~mL}$ reaction vial. It was then supplemented with $18 \mu \mathrm{L} 3 \mathrm{M}$ sodium acetate and $400 \mu \mathrm{L} 99 \%$ ethanol, followed by gentle mixing. The precipitated DNA was centrifuged $60 \mathrm{~min}$ at $6000 \mathrm{~g}$. The DNA pellet was washed with $70 \%$ ethanol, air-dried and then solved in RNAse free $\mathrm{ddH}_{2} \mathrm{O}$. All samples were 
pooled and used for DNA sequencing. In the case of $A$. aegerita AAE-3-13 and A. aegerita AAE-3-32, a modified CTAB method [42] was applied to extract $80 \mu \mathrm{g}$ of genomic DNA per strain. The DNA concentration was measured using a Qubit Fluorometer (Invitrogen, Carlsbad, CA, USA) using the Qubit dsDNA HS Assay Kit (Life Technologies GmbH, Darmstadt, Germany) according to the manufacturer's instructions. RNA was isolated and then pooled from three developmental stages of $A$. aegerita AAE-3: from fruit bodies, vegetative mycelium grown on $2 \%$ malt extract agar plates, and vegetative mycelium derived from liquid YMG cultures as mentioned above. The RNeasy Plant Mini Kit (Qiagen, Hilden, Germany) was used according to the manufacturer's protocol to isolate RNA, which was stored at $-80{ }^{\circ} \mathrm{C}$ until further use. Quality analysis of genomic DNA and total RNA before sequencing, library construction, and sequencing on PacBio (RS II) and Illumina (HiSeq 2500) instruments, was carried out by the commercial sequencing provider Eurofins Genomics (Ebersberg, Germany).

\section{Hybrid assembly of the $A$. aegerita AAE-3 genome sequence using Illumina and PacBio data}

A total of $11.37 \mathrm{~GB}$ of raw sequence data of $A$. aegerita AAE-3 (read length $100 \mathrm{nt}$, insert sizes 300, 800 and $3000 \mathrm{bp}$ ) were generated on an Illumina Hi-Seq-2500 sequencer. Vector trimmed data of all insert libraries were filtered on the basis of Phred quality scores [43]. The minimum overall read quality was set to 25 and the minimum read length was set to $90 \mathrm{nt}$, using Sickle [44]. The two monokaryotic mating-compatible sibling strains A. aegerita AAE-3-13 and A. aegerita AAE-3-32 were also sequenced using a PacBio RS II sequencing platform. PacBio reads of both the sibling strains were corrected with the help of Illumina paired end reads using Proovread [45]. Illumina-corrected reads were further self-corrected using CANU [46]. Corrected PacBio reads of strain A. aegerita AAE-3-13 were assembled using CANU [46] with an error rate set to $2.5 \%$. The resulting scaffolds were merged with Illumina paired end reads using SSPACE [47]. The resulting assembly was further improved by scaffolding using PacBio reads with the SSPACE Long-read hybrid assembler [48]. This step was repeated once again on the resulting scaffolds. Subsequently, Illumina reads were used to fill gaps between the scaffolds using the SSPACE Long-read hybrid assembler. The scaffolds resulting from this were then again assembled with PacBio reads using the SSPACE Longread hybrid assembler which slightly reduced the number of scaffolds but did not increase the genome size. Keeping this final hybrid assembly as a reference, Illumina reads of all three libraries were mapped on the reference to generate a reference-based assembly of the genome of $A$. aegerita AAE-3 using MAQ [49].
To remove ambiguities, an error correction of the reference genome was performed with the help of Illumina reads using Proovread [45]. All scaffolds having more than $90 \%$ of Ns were discarded. To estimate the completeness of the genome sequence resulting from the hybrid assembly, a CEGMA analysis [50] of the reference genome was performed.

\section{Reconstruction of the A. aegerita AAE-3-13 and A. aegerita AAE-3-32 monokaryon genomes}

To reconstruct the genomes of $A$. aegerita AAE-3-13 and $A$. aegerita AAE-3-32, PacBio reads from both strains were mapped individually onto the reference genome of the dikaryon A. aegerita AAE-3 using BLASR [51] and alignments were stored in SAM file format [52]. SAM files were converted to sorted BAM files using SAMTOOLS [52]. The genome sequence of each of the monokaryons was generated by converting sorted BAM files into consensus fastq files using the BAM2CNS module of Proovread.

\section{Gene finding and annotation}

RNASeq data from $A$. aegerita AAE-3 with a read length of $100 \mathrm{nt}$ and a Phred quality score $>25$ were aligned to the genome sequence using TopHat [53]. De novo transcript assembly of RNASeq data was also performed using Trinity [54]. Intron-hints were generated from the TopHat alignment using a perl script. Genemark [55-58] was used to generate a transcript-guided gene model. A spliced alignment of Trinity de novo transcripts with the genome of $A$. aegerita $\mathrm{AAE}-3$ and a spliced alignment based on transcript assemblies were generated using PASA [59]. PASA transcripts were used to generate a training set using Transdecoder. This set was used to train the Augustus gene prediction tool [60]. Using the trained Augustus tool and an exon-intron hint file generated by BLAT [61], another gene model for A. aegerita AAE-3 was constructed. Gene models generated by Augustus, GeneMark-ET, PASA transcript assemblies, the Transdecoder training gene set, and a spliced transcript alignment generated by BLAT and GMAP [62] were used to generate a consensus gene set using the Evidence Modeler (EVM) software [63] with equal weight to all gene models.

To predict genes in the genome sequences of the monokaryotic strains $A$. aegerita AAE-3-13 and $A$. aegerita AAE-3-32, cDNA sequences of $A$. aegerita AAE-3 were mapped onto the genome sequences of the two monokaryons using GMAP with the parameters to map end-to-end cDNA. The resulting gene boundaries for each of the monokaryon genome sequence were saved in GFF file format. Protein-coding genes and protein sequences were extracted from the genome sequences and the GFF files using gffread as implemented in Cufflinks-2.2.1 [64, 65]. 
Functional annotation of protein-coding genes

Amino acid sequences of all protein-coding genes from the dikaryotic strain $A$. aegerita AAE-3 were searched against the translated NCBI non-redundant nucleotide database using BLASTP [66]. Functional annotation of fruiting-related genes (FRGs) was done using InterProScan $[67,68]$, Blast2Go $[69,70]$ and the NCBI CDD database [71-75] Functional annotation of carbohydrate active enzymes (CAZymes) was carried out by using a HMMER search (Version 3.1b2; http://hmmer.org/). A database of translated sequences of all genes present in the GFF file of the dikaryotic strain $A$. aegerita AAE-3 was generated and searched for CAZymes applying the Hidden Markov Models (HMMs) for CAZymes [76]. Agrocybe aegerita proteins allocated to more than one CAZyme group where specified to the CAZyme group with the highest expected value (E-value). In addition, a threshold of $10^{-17}$ for independent E-values was set to dispose false positive hits as recommended by Yin et al. [76]. Functional annotations were added to the GFF file and unique gene IDs were assigned to each gene using in-house developed Perl scripts.

\section{Data access}

To represent the genome and genomic features of all three strains of $A$. aegerita, a web-based genome browser was developed using JBrowse version 1.12.1 $[77,78]$. Fasta sequences of genomes and GFF files for gene features for all three strains were used to visualise the genes and their distribution over the genomes of each strain. Mapping results of RNASeq reads of the dikaryotic strain A. aegerita AAE- 3 in BAM format was also used to represent the transcriptomic support to the genes in the respective strain. All analysed data were also put in the format of a BLAST database to facilitate BLAST searches. Nucleotide sequences of all scaffolds of all three sequenced strains of $A$. aegerita have been deposited in the European Nucleotide Archive (ENA) database under the BioProject accession number PRJEB21917. Phylogeny data have been deposited in the TreeBASE repository via submission ID 22045: http://purl.org/phylo/treebase/phylows/study/ TB2:S22045

\section{Results}

\section{The genome sequence of $A$. aegerita}

The hybrid assembly using the Illumina data of the dikaryotic strain A. aegerita AAE-3 and the PacBio data of one of the monokaryotic sibling strains, A. aegerita AAE-3-13, resulted into 127 scaffolds of 44,852,333 bp combined length. The preliminary reference-based assembly of the genome sequence of only the dikaryon A. aegerita AAE-3 also consisted of 127 scaffolds covering $44,852,333$ bp of the genome. After removing the scaffolds with more than $90 \%$ of Ns, the final genome of $A$. aegerita AAE-3 was represented by 122 scaffolds covering $44,790,776$ bp, with $3.17 \%$ of Ns. The longest scaffold was of 2,759,836 bp and the shortest scaffold was of $2417 \mathrm{bp}$. N50 and L50 of the final genome of $A$. aegerita AAE-3 was 768,404 bp and 20 respectively (Table 1 ).

A CEGMA analysis revealed more than $97 \%$ complete coverage of core eukaryotic genes (Additional file 1: Figure S1). The genomes of the monokaryons $A$. aegerita AAE-3-13 and $A$. aegerita AAE-3-32 were represented by $44,744,304$ bp (120 scaffolds) and 44,730,133 bp (120 scaffolds), respectively (Table 1). CEGMA analyses revealed that the genome completeness in the case of $A$. aegerita AAE-3-13 and A. aegerita AAE-3-32 was above $97 \%$ and $94 \%$, respectively (Additional file 1: Figure S2).

In total, 14,200 protein-coding genes were initially identified within the A. aegerita AAE-3 genome (for details see material and methods). Of these, 87 were incomplete and thus discarded. The final gene set for the A. aegerita AAE-3 genome thus consisted of 14,113 complete protein-coding genes. These were mapped onto the genome sequences of the sibling monokaryons $A$. aegerita AAE-3-13 and $A$. aegerita AAE-3-32. All 14,113 genes mapped onto $A$. aegerita AAE-3-13, and 13,611 genes could be mapped completely. In $A$. aegerita AAE-3-32, 12,951 genes could be mapped completely.

All 14,113 protein-coding genes of A. aegerita AAE-3 had hits to InterProScan databases, and 13,872 genes exhibited a significant match to the NCBI nt (nucleotide) database. Of the 14,113 genes, 8081 had a functional annotation in InterProScan. Referring to the GO (gene ontology) terms molecular function, biological processes and cellular components, a majority of genes were annotated to play role in metabolic processes (Additional file 2)

Table 1 Final genome assembly statistics for A. aegerita AAE-3, A. aegerita $A A E-3-13$ and $A$. aegerita AAE-3-32

\begin{tabular}{llll}
\hline & $\begin{array}{l}\text { A. aegerita } \\
\text { AAE-3 }\end{array}$ & $\begin{array}{l}\text { A. aegerita } \\
\text { AAE-3-13 }\end{array}$ & $\begin{array}{l}\text { A. aegerita } \\
\text { AAE-3-32 }\end{array}$ \\
\hline Number of scaffolds & 122 & 120 & 120 \\
Total size of scaffolds & $44,790,776$ & $44,744,304$ & $44,730,133$ \\
Longest scaffold & $2,759,836$ & $2,758,410$ & $2,756,827$ \\
Shortest scaffold & 2417 & 3316 & 3318 \\
Mean scaffold size & 367,138 & $3,722,869$ & 372,751 \\
Median scaffold size & 233,203 & 240,936 & 240,523 \\
N50 scaffold length & 768,404 & 768,344 & 768,333 \\
L50 scaffold count & 20 & 20 & 20 \\
scaffold \%A & $23.83 \%$ & $24.12 \%$ & $24.10 \%$ \\
scaffold \%C & $24.61 \%$ & $24.82 \%$ & $24.69 \%$ \\
scaffold \%G & $24.61 \%$ & $24.84 \%$ & $24.73 \%$ \\
scaffold \%T & $23.78 \%$ & $24.03 \%$ & $24.00 \%$ \\
scaffold \%N & $3.17 \%$ & $2.18 \%$ & $2.48 \%$ \\
\hline
\end{tabular}


and binding (Additional file 3) as well as to structurally contribute to general cell structure (Additional file 4). Using InterProScan, the majority of genes were annotated as coding for Cytochrome P450 proteins, dehydrogenases/ reductases, and members of the major facilitator superfamily (Additional file 5).

\section{Fruiting-related genes (FRGs)}

A. aegerita AAE-3 is able to complete its life cycle by the formation of typical agaric fruit bodies on agar medium after three weeks, depending on light. In the absence of light, a 'dark stipe' phenotype occurs (Fig. 1). The genome sequence of $A$. aegerita AAE- 3 was searched for putative $A$. aegerita AAE- 3 homologs of genes that had previously been shown to play a role during fruit body (mushroom) formation in A. aegerita or other agaricomycetes (Table 2). These genes were

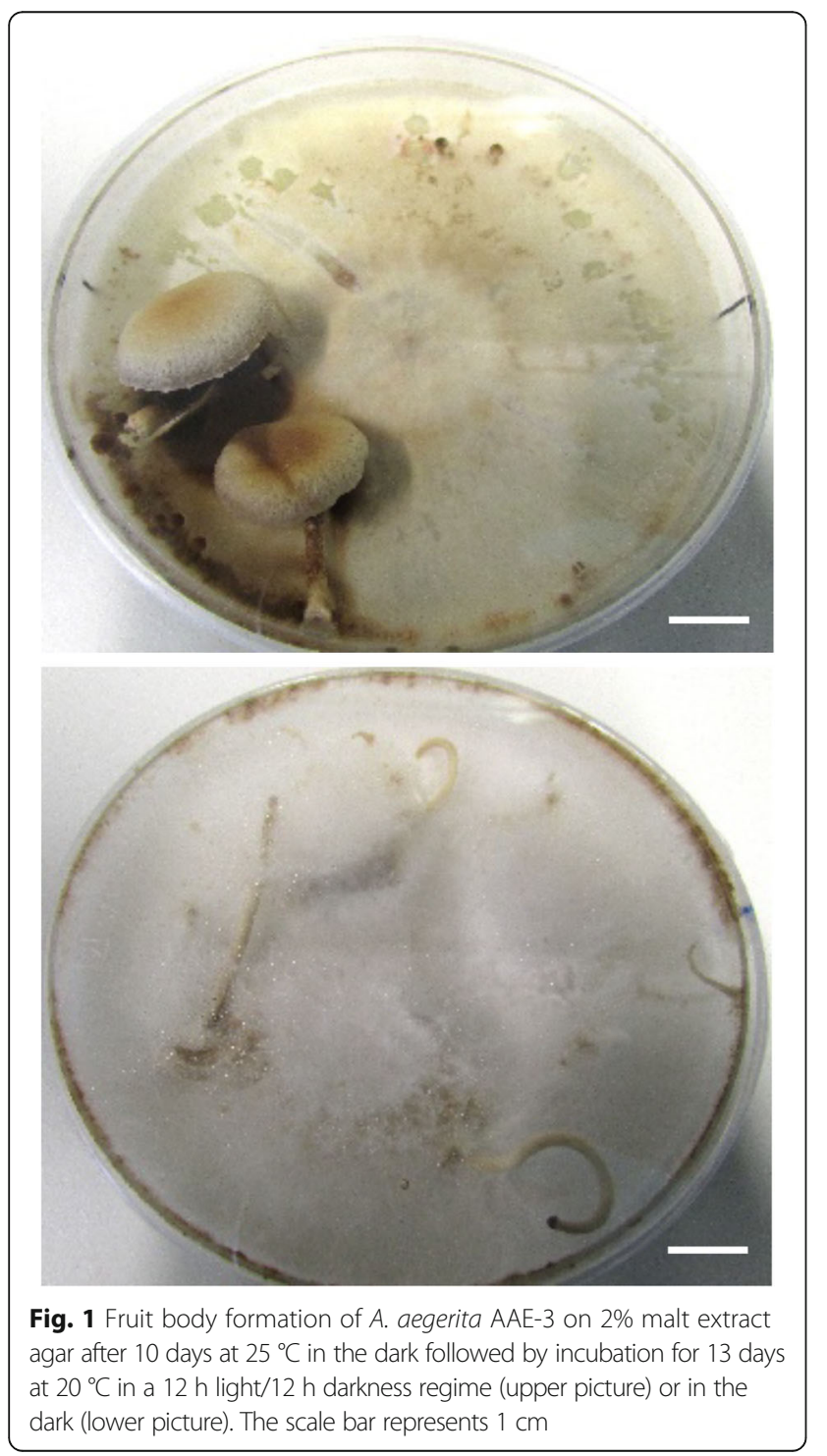

Table 2 Putative homologs of fruiting-related genes (FRGs) in A. aegerita AAE-3

\begin{tabular}{lll}
\hline FRG & Reference & $\begin{array}{l}\text { Gene IDs (=protein IDs) } \\
\text { of putative homolog(s) } \\
\text { in A. aegerita AAE-3 }\end{array}$ \\
\hline BRI1 & Ohm et al. [25] & AAE3_08826 \\
BWC2 & Idnurm and Heitman [107] & AAE3_13841 \\
C2H2 & Ohm et al. [25] & AAE3_10955, AAE3_10959, \\
& & AAE3_10962 \\
EXP1 & Muraguchi et al. [98] & AAE3_02324 \\
FST3 & Ohm et al. [25] & AAE3_09009 \\
FST4 & Ohm et al. [25] & AAE3_11357 \\
GAT1 & Ohm et al. [25] & AAE3_00943 \\
HOM1 & Ohm et al. [25] & AAE3_03904 \\
HOM2 & Ohm et al. [25] & AAE3_01295 \\
PCC1 & Murata et al. [88] & AAE3_01481 \\
CFS1 & Liu et al. [89] & AAE3_01819 \\
DST1 & Terashima et al. [91] & AAE3_10538 \\
DST2 & Kamada et al. [22] & AAE3_02725 \\
ELN3 & Arima et al. [99] & AAE3_00364, AAE3_06792, \\
ICH1 & Muraguchi and Kamada [90] & AAE3_13318 \\
AaPRI1 & Fernandez Espinar and & AAE3_04768 \\
AaPRI2 & Labarère [93] & AAE3_01691 \\
AaPRI3 & Sirand-Pugnet and Labarère [79] & AAE3_14114, AAE3_14115, \\
& & AAE3_13258, AAE3_14116, \\
AaPRI4 & Sirand-Pugnet et al. [19] & AAE3_13242, AAE3_13216, \\
& & AAE3_14117, AAE3_14118 \\
& AAE3_04684, AAE3_04675, \\
& AAE3_04665 AAE3_04667 \\
&
\end{tabular}

termed fruiting-related genes (FRGs). Structural and functional annotation was done using InterProScan and NCBI CDD (Fig. 2) applying the same order of listing the FRGs both in Fig. 2 and Table 2, starting with transcription factor-encoding FRGs and ending with FRGs that have been described from $A$. aegerita SM51 previously. For each known agaricomycete FRG, the gene ID of the A. aegerita AAE-3 gene displaying the highest sequence homology is given. Where applicable, an InterProScan (starting with 'IPR' or 'PTHR')- or NCBI CDDID (starting with 'cd') was provided.

The largest group of genes related to fruit body formation encodes the transcription factors Bri1, Bwc2, C2H2, Exp1, Fst3, Fst4, Gat1, Hom1, Hom2 and Pcc1 (Table 2), originally described from Schizophyllum commune and Coprinopsis cinerea. For all of these genes, we could identify putative $A$. aegerita AAE-3 homologs. In case of $\mathrm{C} 2 \mathrm{H} 2$, three putative $A$. aegerita homologs were present as paralogous copies (Table 2).

The second group of genes involved in fruit body formation encodes a group of functionally diverse proteins, 


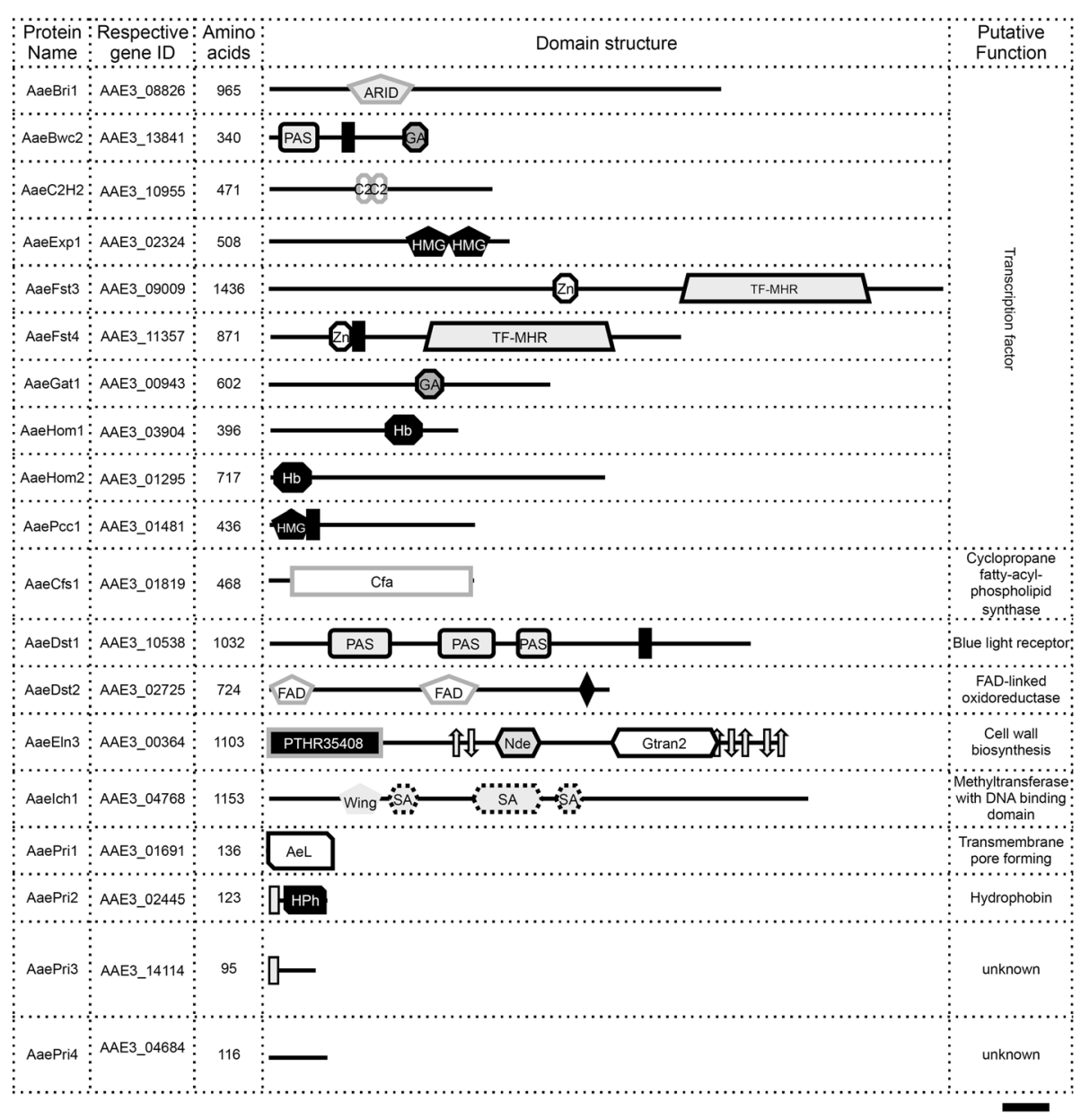

\begin{tabular}{|c|c|c|c|}
\hline \multicolumn{2}{|c|}{ Domain symbols and names (with IPR- or cd-IDs): } & FAD & FAD-binding motif (IPR016166) \\
\hline ARID & ARID DNA-binding domain (IPR001606) & & Berberine-like domain (IPR012951) \\
\hline PAS & PAS domain (IPR000014) & PTHR35408 & Unnamed PANTHER domain \\
\hline & Coil & & Transmembrane domains \\
\hline & $\begin{array}{l}\text { Zinc finger, GATA-type (AaeBwc2: IPR000679) } \\
\text { or NHR/GATA-type (AaeGat1: IPR013088) }\end{array}$ & dST & Nucleo-diphospho-sugar transferase domain (IPR029044) \\
\hline & Zinc finger, C2H2-type (IPR007087) & Gtran2 & Glycosyltransferase 2-like domain (IPR001173) \\
\hline & HMG-box motif (IPR009071) & Wing & Winged helix DNA-binding (IPR011991) \\
\hline $2 n$ & $\begin{array}{l}\text { Zn(2)-C6 fungal-type DNA-binding } \\
\text { domain (IPR001138) }\end{array}$ & $\therefore$ & $\begin{array}{l}\text { S-adenosyl-L-methionine-dependent methyltransferase } \\
\text { domains (IPR029063) }\end{array}$ \\
\hline TF-MHR & Fungal TF-MHR region (cd12148) & AeL & Aegerolysin (IPR009413) \\
\hline & Homeobox domain (IPR001356) & & Hydrophobin (IPR001338) \\
\hline $\mathrm{Cfa}$ & $\begin{array}{l}\text { Cyclopropane fatty-acyl-phospholipid synthase } \\
\text { and related methyltransferases (IPR003333) }\end{array}$ & & Signal peptide \\
\hline
\end{tabular}

Fig. 2 Putative homologs of agaricomycete fruiting-related genes in the genome of A. aegerita AAE-3 were identified by the basic local alignment search tool (BLAST; https://blast.ncbi.nlm.nih.gov/Blast.cgi) using published amino acid sequences of these genes from A. aegerita SM51 (=WT-1), Coprinopsis cinerea okayama7\#130, C. cinerea AmutBmut pab1-1 and Schizophyllum commune H4-8 as query sequences (Additional file 6). Annotations of known functional elements and domains of the respective amino acid sequences were derived from InterProScan (http://www.ebi.ac.uk/interpro) and the NCBI Conserved Domain Database (CDD; https://www.ncbi.nlm.nih.gov/cdd). The scale bar represents 100 amino acids and the following abbreviations of domain names were used: ARID (AT-rich interaction domain) type DNA-binding domain; PAS (Per-Arnt-Sim) domain; HMG (high mobility group) box motif; FAD (flavin adenine dinucleotide); Fungal TF-MHR (transcription factor regulatory middle homology region)

i.e. Cfs1, Dst1, Dst2, Eln3 and Ich1 (Table 2), which have been characterised based on homology to the orthologous genes of $C$. cinerea. For Eln3, three putative $A$. aegerita paralogs were identified (Table 2). Analysing the domain structure of AaeEln3, a so far unnamed Nterminal conserved domain (PTHR35408, amino acids 1-240) was detected in addition to a Nucleotidediphospho-sugar transferase domain (IPR029044, amino 
acids 475-574), and a glycosyltransferase 2-like domain (IPR001173, amino acids 712-936), framed by transmembrane helices, both N-terminally (amino acids 382438) and C-terminally (amino acids 914-1095) (Fig. 2).

The last group of FRGs is made up by four genes (Table 2), which were transcriptionally induced during fruit body formation of the dikaryotic $A$. aegerita wild type strain SM51 (=WT-1) [79]. According to the prediction $A$. aegerita AAE-3 has homologs for each of these FRGs (Table 2). However, in case of AaPri3 [79] and AaPri4 [19] these have undergone paralogisation into eight putative AaPri3-like and four AaPri4-like protein sequences in the $A$. aegerita AAE-3 genome. The A. aegerita AAE-3 homologs of AaPri3 and AaPri4 with highest similarity scores are shown in Fig. 2, encoded by AAE3_14114 and AAE3_04684, respectively. Moreover, a conserved C-terminal sequence motif (CNxxxxxxCxxGGGxCxYNxxTKRCSxxxxMRGxxxPxxCx $\mathrm{xCxC}$ ) was observed when comparing AaePri3 to its putative homologs in S. commune H4-8 (gene IDs XP_003033809 and XP_003027699) and C. cinerea okayama7\#130 (gene ID XP_001841531).

\section{Secreted enzymes with focus on oxidoreductases}

A search for CAZymes using standard settings resulted in 824 genes coding for potential enzymes and carbohydrate-binding modules (CBMs) involved in degradation of polysaccharides and other plant materials (Fig. 3). When applying a more stringent threshold for the E-value $\left(10^{-17}\right)$ the total number was reduced to 476 genes including 206 putative glycoside hydrolases and 126 putative enzymes of the AA family (auxiliary activities of oxidoreductases that act in conjunction with CAZymes), and 12 CBMs. To further annotate this set in more detail, AA families were manually assigned by aligning the deduced amino acid sequence of all proteins of each subgroup to one or more reference sequences (http://www.cazy.org/Auxiliary-
Activities.html), including AA1_1 and AA1_2 (Additional file 1: Figure S3), AA2 (Additional file 1: Figure S4), AA3_2, AA3_3 and AA8-AA3_1 (Additional file 1: Figure S5), AA8AA3_1 and AA12 (Additional file 1: Figure S6), AA5_1 (Additional file 1: Figure S7), AA6 (Additional file 1: Figure S8), AA7 (Additional file 1: Figure S9) and AA9 (Additional file 1: Figure S10). This resulted in a reduction of genes coding for AA proteins from 126 to 86 (Table 3). Representatives of two other secretory peroxidase families in the $A$. aegerita genome, i.e. dye-decolourising peroxidases (DyP) and unspecific peroxygenases (UPO), were identified by BLASTP searches using reference sequences. Three DyP genes (AAE3_06734, AAE3_09015, AAE3_12346) of the subfamily D [80] are present in the genome (Additional file 1: Figure S11). Altogether 18 UPO genes were identified (Additional file 1: Figure S12), 16 of which belong to the so-called "long" UPOs (AAE3_00227 to AAE3_00237, AAE3_04643, AAE3_05814, AAE3_10946, AAE3_11945, AAE3_12863), and two to the "short" UPOs (AAE3_06358, AAE3_08521). Of the UPO-encoding genes, AAE3_00227 to AAE3_00232 and AAE3_00234 to AAE3_00237 were found to be located in close proximity on scaffold 1 in a successive orientation suggesting co-functionality.

Two genes (AAE3_08832 and AAE3_13544) have been grouped into the AA4 family containing vanillyl-alcohol oxidases (VAO) by HMMER search. However, they do not contain the specific FAD-binding motif present in already-characterised VAO [81, 82], and thus have been unassigned. The predicted class II peroxidases, i.e. members of the AA2 family, were subdivided after a phylogenetic analysis (Additional file 1: Figure S4) into one typical manganese peroxidase (AAE3_01449) and three atypical manganese peroxidases, missing either one (AAE3_06269, AAE3_10529) or two (AAE3_08350) glutamic acid residues involved in $\mathrm{Mn}^{2+}$-binding. In

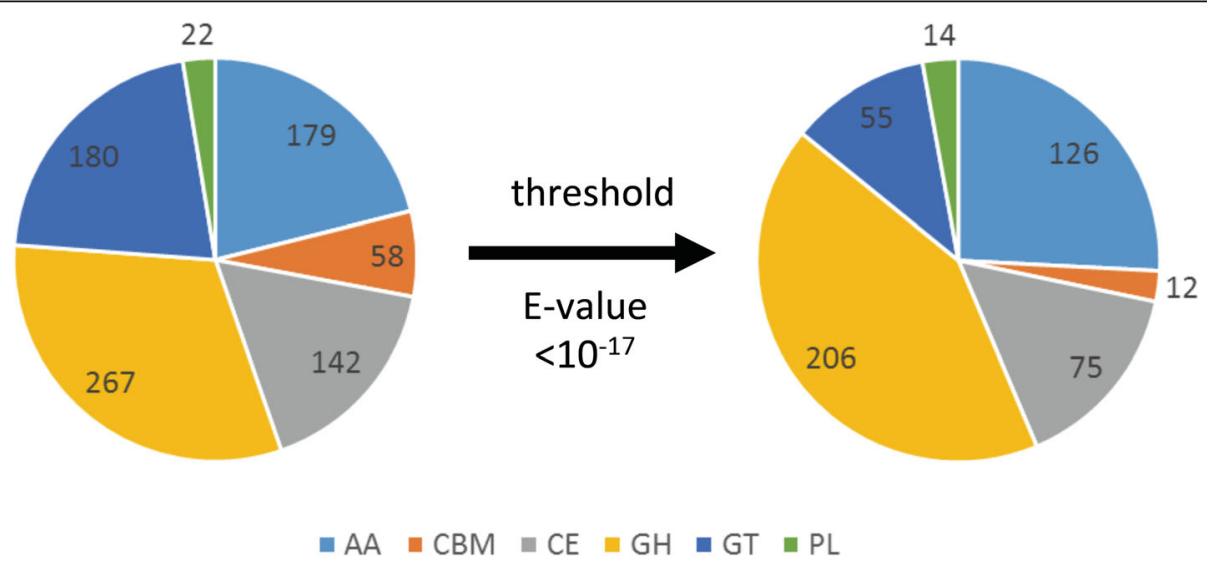

Fig. 3 Distribution of the different CAZymes within the A. aegerita genome as obtained after HMMER search without (left) and with (right) an E-value threshold of $10^{-17}$. The following abbreviations were used: AA (auxiliary activity), CBM (carbohydrate-binding module), CE (carbohydrate esterase), GH (glycoside hydrolase), GT (glycosyl transferase) and PL (polysaccharide lyase) 
Table 3 Number of genes assigned to the CAZy families by reviewing and prediction (HMM)

\begin{tabular}{|c|c|c|c|}
\hline $\begin{array}{l}\text { CAZy } \\
\text { family } A A^{a}\end{array}$ & Name & reviewed & predicted \\
\hline$\overline{\mathrm{AA} 1 \_1}$ & laccase sensu stricto & 14 & 15 \\
\hline AA1_2 & ferroxidases & 1 & \\
\hline AA1_3 & laccase-like multi-copper oxidases & 0 & \\
\hline AA2 & class II fungal peroxidases & 4 & 8 \\
\hline AA3_1 & cellobiose dehydrogenase & 0 & 28 \\
\hline AA3_2 & $\begin{array}{l}\text { aryl-alcohol oxidase/ glucose-1- } \\
\text { oxidase }\end{array}$ & 25 & \\
\hline AA3_3 & alcohol oxidase & 3 & \\
\hline AA3_4 & pyranose oxidase & 0 & \\
\hline AA4 & vanillyl-alcohol oxidase & 0 & 2 \\
\hline AA5_1 & glyoxal oxidase & 8 & 14 \\
\hline AA5_2 & galactose oxidase & 0 & \\
\hline AA6 & 1,4-benzoquinone reductase & 3 & 3 \\
\hline AA7 & glucooligosaccharide oxidase & 2 & 30 \\
\hline AA8-AA3_1 & iron reductase domain & 1 & 1 \\
\hline AA9 & lytic polysaccharide monooxygenase & 21 & 21 \\
\hline $\mathrm{AA} 12$ & $\begin{array}{l}\text { pyrroloquinoline quinone-dependent } \\
\text { oxidoreductase }\end{array}$ & 4 & 4 \\
\hline
\end{tabular}

${ }^{\mathrm{a}} \mathrm{AA}$ (auxiliary activities of redox active enzymes in conjunction with CAZymes)

addition, the HMMER search assigned three intracellular ascorbate peroxidases (APx) and one cytochrome c peroxidase $(\mathrm{CcP})$ to the AA2 family.

Other AA families, i.e. AA1, AA6, AA8, AA9 and AA12, were grouped to reference genes as expected.

The 15 predicted multicopper-oxidases (MCO) split into the AA1 family with 14 genes assigned to the subfamily AA1_1 (laccases sensu stricto) and one gene assigning to the subfamily AA1_2 (ferroxidases). Of the 14 laccase genes, two protein sequences seemed incomplete, missing either the C-terminus (AAE_12795) or N-terminus (AAE3_12295), thus not containing all expected copper-binding residues.

The gene AAE3_04795 has been assigned to the mixed cellobiose dehydrogenase (CDH) family AA3_1/AA8, due to the presence of an iron reductase domain within its sequence (Additional file 1: Figure S5 and Additional file 1: Figure S6, respectively). Nevertheless, AAE3_04795 was grouped into the AA8 family (Table 3) with an E-value of $10^{-292}$ in the HMMER search. Some closely related enzymes group into the AA12 family.

The four genes assigned to the pyrroloquinoline quinone-dependent (PQQ) oxidoreductases (AA12) family combining the iron reductase domain of the AA8 family with a PQQ-dependent dehydrogenase domain [83], divided into two long and two short ones. The long AA12 proteins (AAE3_04971 and AAE3_04974) showed the highest similarity to the PQQ-dependent sugar dehydrogenase (PQQ-SDH) from C. cinerea [83]. The shorter two genes are lacking the iron reductase domain, but do have the PQQ-binding residues. However, AAE3_05242 is lacking the histidine residue proposed to be involved in catalytic activity, present in all other $A$. aegerita AA12 proteins. Similarly to the $C$. cinerea PQQ-SDH (CcSDH [83]), AAE3_04974 has a CBM1 module at its C-terminus, which is missing in AAE3_04971.

Within the AA6 family, all the three predicted 1,4benzoquinone reductases $(\mathrm{BQR})$, showed a high similarity to a characterised $\mathrm{BQR}$ of the brown-rot fungus Gloeophyllum trabeum with E-values between $10^{-82}$ and $10^{-85}$ in BLAST searches (Additional file 1: Figure S8). All 21 AA9-related sequences of $A$. aegerita showed the copper-binding residues (two histidines and one tyrosine) present in lytic polysaccharide monooxygenases (LPMOs) in accordance to Li et al. [84]. The only exception was AAE3_03716, with a lysine and an asparagine instead of the two histidine residues and, thus, suggesting a different function. Two of the predicted AA9 members (AAE3_05891 and AAE3_05893) clustered apart from the other LPMOs. They show the typical copper-binding residues, but have only three exons compared to the other LMPOs, which have five to ten exons.

\section{Discussion}

\section{General genome features}

The genome assembly of A. aegerita AAE- 3 is comparable in fragmentation and continuity to other high quality mushroom genomes [23, 24, 85]. In terms of coding capacity, A. aegerita is similar to other well-known agaricomycetes such as Agaricus bisporus, Coprinopsis cinerea, and Schizophyllum commune [23, 24, 85]. The genome assembly is about $44 \mathrm{Mb}$ in size comparable to the assemblies for related members of the Agaricales, which range from $35 \mathrm{Mb}$ to $65 \mathrm{Mb}$ [23, 24, 85-87].

\section{Putative A. aegerita AAE-3 homologs of fruiting-related genes}

Ten putative homologs of known fruiting genes (FRGs) encoding transcription factors have been found. The high mobility group (HMG)-box transcription factor Pcc1 from $C$. cinerea, which has been reported to be distinct from $A$ and $B$ mating type genes, was shown to permit fruiting already from monokaryotic mycelium when carrying a particular recessive mutation [88]. It is not known, if a mutation in the putative $A$. aegerita homolog AaePcc1 might also be sufficient to provoke the pseudo-homokaryotic fruiting (PHF) phenotype, which has been previously reported for $A$. aegerita as a result of mating type switching [5]. In dikaryotic mycelium, the initial steps of fruiting in S. commune are mediated by transcription factors such as Bri1, Hom2 and Fst4, 
where they are crucial for the initiation of fruiting by asymmetrical colony growth and aggregation leading to fruit body initial formation [25]. An ortholog of the Cfs1 protein, described from $C$. cinerea, is also present in $A$. aegerita. In C. cinerea, it plays an important role in fruit body development, as it has been reported to trigger the formation of the light-induced fruit body initials from undifferentiated hyphae. In addition, Cfs1 also seemed to be acting at later stages of fruit body development in this mushroom [89]. The next step of fruit body development is the differentiation of primordia from fruit body initials. This step was reported to be influenced by $\mathrm{C} 2 \mathrm{H} 2$ and Fst3 [25]. Interestingly, three putative homologs of S. commune $\mathrm{C} 2 \mathrm{H} 2$ could be found within the A. aegerita AAE- 3 genome including the typical adjacent $\mathrm{C} 2 \mathrm{H} 2$ zinc-finger domains. While this implies that all three paralogs could be functional transcription factors, their function und potential redundancy needs to be evaluated in future studies.

With respect to the subsequent step of fruit body development, the development of a primordial cap and stipe, ich1, for which a homolog is present in A. aegerita as well, seems to play an important role in $C$. cinerea, as a spontaneous mutant in the progeny of a normal $C$. cinerea fruit body collected from nature exhibited figshaped primordia that are unable to develop further into mushrooms [90]. After the formation of the primordial cap at the apex of the primordial shaft, under proper light conditions, the primordial stipe and cap further enlarge and develop during the blue light-controlled development of fruit body primordia into young fruit bodies in C. cinerea. Essential to this are the genes Dst1 and Dst2, for which we could also detect putative homologs in $A$. aegerita. They are responsible for the 'dark stipe' or 'etiolated stipe' phenotype of $C$. cinerea, which occurs, e.g. when primordia are kept in darkness $[22,91,92]$. Such a 'dark stipe' phenotype could also be observed in the wild type dikaryon $A$. aegerita AAE-3 in case of light deprivation during early fruit body development [27]. The transcriptional induction of four additional genes during primordium development supposedly encoding different factors implicated in fruit body formation [19, 79, 93, 94], was observed in A. aegerita. The first of these genes, corresponding to AaePril, has been discussed to show structural similarity to a fungal hemolysin from Aspergillus fumigatus [93] and is nearly identical to the sequence of the $A$. aegerita hemolysin aegerolysin [95]. Aegerolysins are a unique family of pore-forming proteins with haemolytic activity $[95,96]$, which have also been described from bacteria, moulds, the oyster mushroom Pleurotus ostreatus, and from plants. Aegerolysins themselves were reported to enhance the formation of primordia and to also stimulate the development of primordia to young fruit bodies, which suggests them to play an important role in fruiting [97]. The second of those genes, which is represented by AaePRI2, was characterised as a fruitingspecific hydrophobin and described to feature eight hydrophobin-characteristic cysteine residues as well as a putative signal peptide for secretion [94]. In agreement with the protein sequence features of the third primordium-induced gene characterised by Sirand-Pugnet and Labarère [79], all eight putative $A$. aegerita AAE-3 homologs of this gene (see Table 2) have a predicted $\mathrm{N}$ terminal secretion signal peptide and are rich in cysteine and glycine. As there are so many potential paralogs, functional redundancy among them is conceivable, but stagespecificity or other regulatory functions cannot be ruled out at present.

In contrast to the high number of genes associated to primordium development, only a small number of genes has been described from $C$. cinerea that play a role during fruit body maturation [98, 99]. These genes were characterised from two different $C$. cinerea 'elongationless' mutants, the eln 2 and eln 3 mutant, which exhibit an arrest in stipe elongation [99, 100], and two $C$. cinerea 'expansionless' mutants carrying a mutation in the gene coding for Exp1, which triggers cap expansion [98]. However, putative A. aegerita homologs could only be predicted in the case of Eln3 and Exp1, suggesting a lower degree of conservation of fruit body maturationassociated genes.

Summarising the repertoire of FRGs in A. aegerita AAE-3 in comparison with other model mushrooms, two aspects might be promising to pursue in future studies. Among the FRGs of A. aegerita AAE-3, AaePRI1 might be a most interesting candidate FRG for prospective characterisation by functional genetics approaches. The putative aegerolysin protein encoded by AaePRII might be an important regulator of agaricomycete fruiting productivity since the aegerolysin protein family member ostreolysin from $P$. ostreatus has been shown to enhance fruit body development [97]. Furthermore, a paralogisation was observed for a number of $A$. aegerita AAE-3 FRGs, i.e. AaeELN3, AaeC2H2, AaePRI3 and AaePRI4, which suggests a more complex genetic regulation of fruit body development in A. aegerita in comparison to other model mushrooms.

\section{Enzymes of the AA family}

Apart from exhibiting an archetypal mushroom phenotype and thus providing a potential model for fruit body development, A. aegerita is well equipped with enzymes for degrading biopolymers and thus may also provide insights into the decomposition of wood and other plant substrates. Agrocybe aegerita is usually cultured on lignocellulose-containing substrates. It was, however, reported to be an unspecific white-rot fungus according to its rotting patterns [40]. Comparing the amount of genes coding for CAZymes relevant for lignin degradation 
reveals more similarity of $A$. aegerita to white-rot fungi than to litter decomposers, such as $C$. cinerea and $A$. bisporus possessing only one and two genes of the AA2 family, respectively, as well as less UPO genes (Additional file 1: Figure S13). The ligninolytic ability of $A$. aegerita was documented for wheat straw and beech wood as well as for side streams of the food industry, but was lower as compared to specialised white-rot fungi [31, 40]. When cultivated on beech wood, $A$. aegerita showed similar laccase activities as typical white-rot fungi, but was lacking $\mathrm{MnP}$ activity [40]. However, genes coding for this peroxidase were found to be present in its genome in the present study, suggesting regulated expression. This may be explained by compensation through the production of unspecific peroxygenases (UPOs) that were described for the first time in A. aegerita $[37,101]$ and might be the basis for the high versatility of the fungus in terms of the oxyfunctionalisation reactions. This is in accordance with a transcriptomic approach [11], in which only low expression levels of MnP genes on complex media were found, but high levels of long UPO transcripts. It is noteworthy that Isikhuemhen et al. [33] detected peroxidase activity when growing $A$. aegerita on a wheat-straw-based substrate, even if laccase activity exceeded that of peroxidase up to ten times in this setting. The relatively high laccase activity of A. aegerita is comparable to other white-rot fungi and may reflect the number of $\mathrm{MCO}$ genes found in its genome. Most white-rot fungi have five to $15 \mathrm{MCO}$ genes [102], most of which belong to the CAZy family AA1_1, also known as the sensu-strictolaccases [103]. Agrocybe aegerita has 13 genes coding for sensu-stricto-laccases of subfamily 1 and one gene coding for a putative laccase of the subfamily 2 . Interestingly, the latter gene (AAE3_12281) is more similar to a laccase of the litter decomposer Coprinopsis cinerea and not with the respective laccase of the white-rotter Pleurotus ostreatus LACC2 (also known as POXA3).

Other enzymes of $A$. aegerita belonging to the AA family were reported to oxidise aromatic alcohols, such as veratryl alcohol and benzyl alcohol, with molecular oxygen as co-substrate while delivering $\mathrm{H}_{2} \mathrm{O}_{2}$ [37, 40]. The AA3 group is the largest group amongst the $\mathrm{H}_{2} \mathrm{O}_{2}$ generating enzymes in A. aegerita. $\mathrm{H}_{2} \mathrm{O}_{2}$ is needed for the functioning of UPOs, DyPs and class II peroxidases of the AA2 family, all present in the A. aegerita genome. In the proteomic approach of Wang et al. [11], peptides fitting to $A$. aegerita AAE-3 DyP-type peroxidase AAE3_12346 were detected. Furthermore, in that study, sequences fitting to $\mathrm{H}_{2} \mathrm{O}_{2}$-producing glyoxal oxidase AAE3_06793 of this study were found. In comparison to other basidiomycete genomes, the number of genes grouping into the AA3_2 subfamily seems to be rather high [85, 104] (Additional file 1: Figure S13). Overall, genes of the AA3_2 subfamily seem to be more pronounced in white-rot than in brown-rot fungi, which is consistent with the fact that brown-rot fungi do not have genes of the AA2 family. In addition, the $A$. aegerita genome contains four and eleven genes coding for putative GH6 and GH7 enzymes, respectively, also suggesting a white-rot decay [102]. Of these putative GH enzymes, three GH7 (AAE3_12287, AAE3_05957, AAE3_05953) and one GH6 (AAE3_13829) as well as 26 other putative CAZymes, amongst others the LMPOs (see Additional file 1: Figure S10) harbour a C-terminal CBM1 domain underpinning the lignocellulolytic ability of $A$. aegerita. Although A. aegerita is known as a whiterot fungus, its enzyme equipment differs from that of prototypical white-rot fungi, in line with the substrate versatility of this fungus. However, litter-decomposing fungi, such as $A$. bisporus and $C$. cinerea, which are also able to degrade lignin, show some similarities to A. aegerita in terms of their enzyme inventory (Additional file 1: Figure S13). For instance, the genome of $A$. aegerita contains 21 genes coding for putative hydrolases acting on $\beta$ linked polysaccharides grouped into the CAZy glycoside hydrolase family GH5 (Additional file 1: Figure S14) similar to the button mushroom, A. bisporus, with 19 GH5 genes and more than twice the number of GH5 genes normally found in wood-colonising white-rot fungi [85]. A similar pattern can be observed with respect to UPO genes, of which $A$. bisporus carries 24, while $A$. aegerita carries 18 . This is far more than observed for classical white-rot basidiomycetes sequenced so far, with the exception of Auricularia subglabra, which features 16 UPO genes.

However, the comparisons with respect to CAZymes is based on a comparison of basidiomycete genomes and, thus, needs to be treated with caution, as only few of these enzymes have been studied in detail in terms of their function. As a consequence, predictions concerning degradation characteristics are fraught with uncertainty. Further studies monitoring the expression profiles of the lignocellulolytic CAZy genes $[105,106]$ in A. aegerita cultures and measurements of enzymatic activity need to be conducted and assessed in order to elucidate the function of enzymes involved in the degradation of recalcitrant substrates.

\section{Conclusion}

In summary, the archetypal mushroom morphology, the versatile biopolymer degradation potential, and the culinary quality of $A$. aegerita render this fungus an interesting model organism for studying fruit body development, biodegradation and aroma production. The annotated genome sequence provided in this study is a first step in this direction, which needs to be followed up by further studies investigating the possibility of genetic manipulation and, potential application of the results from this for industrial biotechnology, directed breeding, and commercial 
mushroom farming. Once genetic manipulation of $A$. aegerita is achieved, its white-rot potential, the use of its CAZy family enzymes for biotechnology (e.g. for biopolymer degradation), and its archetypal mushroom formation can be investigated in detail.

\section{Additional files}

Additional file 1: Supplementary Figures. (PDF 1068 kb)

Additional file 2: Table S1. Agrocybe aegerita AAE-3 genes in subcategories of GO term "molecular function". (DOCX 31 kb)

Additional file 3: Table S2. Agrocybe aegerita AAE-3 genes in subcategories of GO term "biological processes". (DOCX $31 \mathrm{~kb}$ )

Additional file 4: Table S3. Agrocybe aegerita AAE-3 genes in subcategories of GO term "cellular components". (DOCX $31 \mathrm{~kb}$ )

Additional file 5: Table S4. Annotation of Agrocybe aegerita AAE-3 genes using InterProScan. (DOCX 254 kb)

Additional file 6: Table S5. Proteins encoded by fruiting-related genes from different agaricomycetes species. (DOCX $34 \mathrm{~kb}$ )

\section{Abbreviations}

AA: Auxiliary activity; ARID: AT-rich interaction domain; bp: basepair(s); BQR: 1,4-benzoquinone reductase; CAZyme: Carbohydrate active enzyme; CBM: Carbohydrate-binding module; CDD: Conserved Domain Database; CDH: Cellobiose dehydrogenase; CE: Carbohydrate esterase; CEGMA: Core eukaryotic gene mapping approach; DyP: Dye-decolorising peroxidase; FAD: Flavin adenine dinucleotide; FRG: Fruiting-related gene; GH: Glycoside hydrolase; GO: Gene ontology; GT: Glycosyl transferase; HMG: High mobility group; HMM: Hidden Markov Model; LMPO: Lytic polysaccharide monooxygenase; Mb: Megabase(s); MCO: Multicopper oxidase; MnP: Manganese peroxidase; NCBI: National Center for Biotechnology Information; nt: Nucleotide(s); PAS: Per-Arnt-Sim domain; PL: Polysaccharide lyase; PQQ: Pyrroloquinoline quinonedependent; TF-MHR: Transcription factor regulatory middle homology region; UPO: Unspecific peroxygenase; VAO: Vanillyl-alcohol oxidase

\section{Acknowledgements}

We thank Irina Solovyeva for carrying out genomic DNA extraction from $A$. aegerita $\mathrm{AAE}-3-13$ and $A$. aegerita AAE-3-32.

\section{Funding}

This study has been supported by the LOEWE excellence funding initiative, in the framework of the cluster for Integrative Fungal Research (IPF).

\section{Availability of data and materials}

The nucleotide sequences of all scaffolds of all three genome-sequenced strains of A. aegerita supporting the conclusions of this article are available in the European Nucleotide Archive (ENA) repository under the BioProject accession number PRJEB21917 and are also available through our A. aegerita Genome Browser: http://www.thines-lab.senckenberg.de/agrocybe_genome Phylogeny data including alignments have been deposited in the TreeBASE repository under the submission ID 22045: http://purl.org/phylo/treebase/ phylows/study/TB2:S22045

\section{Authors' contributions}

$\mathrm{FH}, \mathrm{MR}$, HK, and MT conceived the study; BM, DKG, FH, HK, MR, MJP, RS, VK, and $\mathrm{RH}$ performed experiments and analysed data; DKG, FH, HK, MR, and MT wrote the manuscript, with contributions from the other authors. All authors have read and approved the final manuscript.

\section{Ethics approval and consent to participate}

Not applicable.

\section{Consent for publication}

Not applicable.

\section{Competing interests}

The authors declare that they have no competing interests.

\section{Publisher's Note}

Springer Nature remains neutral with regard to jurisdictional claims in published maps and institutional affiliations.

\section{Author details}

${ }^{1}$ Senckenberg Biodiversity and Climate Research Centre (BiK-F), Frankfurt a. M., Germany. ${ }^{2} J u n i o r$ Research Group Genetics and Genomics of Fungi, Senckenberg Gesellschaft für Naturforschung, Frankfurt a. M., Germany. ${ }^{3}$ Institute of Ecology, Evolution and Diversity, Goethe University Frankfurt, Frankfurt a. M., Germany. ${ }^{4}$ Institute of Food Chemistry and Food Biotechnology, Justus Liebig University Giessen, Giessen, Germany. ${ }^{5}$ LOEWE Cluster of Integrative Fungal Research (IPF), Frankfurt a. M., Germany. ${ }^{6}$ International Institute (IHI) Zittau, Technische Universität Dresden, Zittau, Germany. 'Project Group "Bioresources", Fraunhofer IME, Giessen, Germany. ${ }^{8}$ University of Applied Sciences Zittau/Görlitz, Zittau, Germany. ${ }^{9}$ Department of Biology, Microbiology, Utrecht University, Utrecht, The Netherlands.

Received: 26 August 2017 Accepted: 29 December 2017

Published online: 15 January 2018

\section{References}

1. Walther $\mathrm{G}$, Weiss M. Anamorphs of the Bolbitiaceae (Basidiomycota, Agaricales). Mycologia. 2006;98:792-800.

2. Esser $\mathrm{K}$, Semerdžieva M, Stahl U. Investigations on the genetics of the basidiomycete Agrocybe aegerita: I. A correlation between the time of fruiting body production and monokaryotic fruiting and its importance for breeding and morphogenesis. Theor Appl Genet. 1974;45:77-85.

3. Nauta MM. Genus Agrocybe. In: Noordeloos ME, Kuyper TW, Velinga EC, editors. Flora Agaricina Neerlandica, vol. 6. Boca Raton: CRC Press, Taylor \& Francis Group; 2005. p. 204-21.

4. Uhart M, Albertó E. Morphologic characterization of Agrocybe cylindracea (Basidiomyceta, Agaricales) from America, Europe and Asia. Revista Mexicana de Micología. 2007;24:9-18.

5. Labarère J, Noël T. Mating type switching in the tetrapolar basidiomycete Agrocybe aegerita. Genetics. 1992;131:307-19.

6. Roca E, D'Errico E, Izzo A, Strumia S, Esposito A, Fiorentino A. In vitro saprotrophic basidiomycetes tolerance to pendimethalin. International Biodeterioration \& Biodegradation. 2009;63:182-6.

7. Stamets P. Growth parameters for gourmet and medicinal mushroom species. In: Stamets $P$, editor. Growing gourmet and medicinal mushrooms. Berkeley: Ten Speed Press; 1993. p. 211-418.

8. Tsai S-Y, Tsai H-L, Mau J-L. Non-volatile taste components of Agaricus blazei, Agrocybe cylindracea and boletus edulis. Food Chem. 2008;107:977-83.

9. Uhart M, Piscera JM, Albertó E. Utilization of new naturally occurring strains and supplementation to improve the biological effciency of the edible mushroom Agrocybe cylindracea. J Ind Microbiol Biotechnol. 2008;35:595-602.

10. Kleofas V, Sommer L, Fraatz MA, Zorn H, Rühl M. Fruiting body production and aroma profile analysis of Agrocybe aegerita cultivated on different substrates. Natural. Resources. 2014;5:233-40.

11. Wang M, Gu B, Huang J, Jiang S, Chen Y, Yin Y, et al. Transcriptome and proteome exploration to provide a resource for the study of Agrocybe aegerita. PLoS One. 2013;8:e56686.

12. Esser K, Meinhardt FA. Common genetic control of dikaryotic and monokaryotic fruiting in the basidiomycete Agrocybe aegerita. Mol Gen Genet. 1977;155:113-5.

13. Esser K, Saleh F, Meinhardt F. Genetics of fruit body production in higher basidiomycetes II. Monokaryotic and dikaryotic fruiting in Schizophyllum commune. Curr Genet. 1979;1:85-8.

14. Meinhardt F, Esser K. Genetic studies of the basisdiomycete Agrocybe aegerita: part 2: genetic control of fruit body formation and its practical implications. Theor Appl Genet. 1981;60:265-8.

15. Meinhardt F, Leslie JF. Mating types of Agrocybe aegerita. Curr Genet. 1982; 5:65-8.

16. Wessels JG. Fruiting in the higher fungi. Adv Microb Physiol. 1993;34:147-202.

17. Kües U. Life history and developmental processes in the basidiomycete Coprinus cinereus. Microbiol Mol Biol Rev. 2000;64:316-53.

18. Kamada T. Molecular genetics of sexual development in the mushroom Coprinus cinereus. BioEssays. 2002;24:449-59. 
19. Sirand-Pugnet $P$, Santos $C$, Labarère J. The aa-Pri4 gene, specifically expressed during fruiting initiation in the Agrocybe aegerita complex, contains an unusual CT-rich leader intron within the $5^{\prime}$ uncoding region. Curr Genet. 2003; 44:124-31.

20. Palmer GE, Horton JS. Mushrooms by magic: making connections between signal transduction and fruiting body development in the basidiomycete fungus Schizophyllum commune. FEMS Microbiol Lett. 2006;262:1-8.

21. Wälti MA, Villalba C, Buser RM, Grünler A, Aebi M, Künzler M. Targeted gene silencing in the model mushroom Coprinopsis cinerea (Coprinus cinereus) by expression of homologous hairpin RNAs. Eukaryot Cell. 2006:5:732-44.

22. Kamada T, Sano H, Nakazawa T, Nakahori K. Regulation of fruiting body photomorphogenesis in Coprinopsis cinerea. Fungal Genet Biol. 2010;47(11): 917-21.

23. Ohm RA, de Jong JF, Lugones LG, Aerts A, Kothe E, Stajich JE, et al. Genome sequence of the model mushroom Schizophyllum commune. Nat Biotechnol. 2010;28:957-63.

24. Stajich JE, Wilke SK, Ahrén D, CH A, Birren BW, Borodovsky M, et al. Insights into evolution of multicellular fungi from the assembled chromosomes of the mushroom Coprinopsis cinerea (Coprinus cinereus). Proc Natl Acad Sci U S A. 2010;107:11889-94.

25. Ohm RA, de Jong JF, de Bekker C, Wösten HA, Lugones LG. Transcription factor genes of Schizophyllum commune involved in regulation of mushroom formation. Mol Microbiol. 2011;81:1433-45.

26. Knabe N, Jung EM, Freihorst D, Hennicke F, Horton JS, Kothe E. A centra role for Ras1 in morphogenesis of the basidiomycete Schizophyllum commune. Eukaryot Cell. 2013;12:941-52.

27. Herzog R, Solovyeva I, Rühl M, Thines M, Hennicke F. Dikaryotic fruiting body development in a single dikaryon of Agrocybe aegerita and the spectrum of monokaryotic fruiting types in its monokaryotic progeny. Mycol Prog. 2016;15: 947-57.

28. Pelkmans JF, Lugones LG, Wösten HAB. Fruiting body formation in basidiomycetes. In: Wendland J, editor. Growth, differentiation and sexuality. Cham: springer; 2016. p. 387-405.

29. Sánchez C. Cultivation of Pleurotus ostreatus and other edible mushrooms. Appl Microbiol Biotechnol. 2010;85:1321-37.

30. Okuda Y, Murakami S, Honda Y, Matsumoto T. An MSH4 homolog, stpp1, from Pleurotus pulmonarius is a "silver bullet" for resolving problems caused by spores in cultivated mushrooms. Appl Environ Microbiol. 2013;79:4520-7.

31. Nicolini L, von Hunolstein C, Carilli A. Solid state fermentation of orange peel and grape stalks by Pleurotus ostreatus, Agrocybe aegerita, and Armillariella mellea. Appl Microbiol Biotechnol. 1987;26:95-8.

32. Philippoussis A, Zervakis G, Diamantopoulou P. Bioconversion of agricultural lignocellulosic wastes through the cultivation of the edible mushrooms Agrocybe aegerita, Volvariella volvacea and Pleurotus spp. World J Microbiol Biotechnol. 2001;17:191-200.

33. Isikhuemhen OS, Mikiashvili NA, Kelkar V. Application of solid waste from anaerobic digestion of poultry litter in Agrocybe aegerita cultivation: mushroom production, lignocellulolytic enzymes activity and substrate utilization. Biodegradation. 2009;20:351-61.

34. Sun H, Zhao CG, Tong X, Qi YPA. Lectin with mycelia differentiation and antiphytovirus activities from the edible mushroom Agrocybe aegerita. J Biochem Mol Biol. 2003;36:214-22.

35. Liang Y, Lin JC, Wang K, Chen YJ, Liu HH, Luan R, et al. A nuclear ligand MRG15 involved in the proapoptotic activity of medicinal fungal galectin AAL (Agrocybe aegerita lectin). Biochim Biophys Acta. 2010;1800:474-80.

36. Reverberi M, Di Mario F, Tomati U. Beta-glucan synthase induction in mushrooms grown on olive mill wastewaters. Appl Microbiol Biotechnol. 2004;66:217-25.

37. Ullrich R, Nüske J, Scheibner K, Spantzel J, Hofrichter M. Novel haloperoxidase from the agaric basidiomycete Agrocybe aegerita oxidizes aryl alcohols and aldehydes. Appl Environ Microbiol. 2004;70:4575-81.

38. Hofrichter M, Kellner H, Pecyna MJ, Ullrich R. Fungal unspecific Peroxygenases: Heme-thiolate proteins that combine peroxidase and cytochrome P450 properties. In: Hrycay EG, Bandiera SM, editors. Monooxygenase, peroxidase and Peroxygenase properties and mechanisms of cytochrome P450. Cham: springer; 2015. p. 341-68.

39. Kinne M, Poraj-Kobielska M, Ullrich R, Nousiainen P, Sipilä J, Scheibner K, et al. Oxidative cleavage of non-phenolic $\beta-0-4$ lignin model dimers by an extracellular aromatic peroxygenase. Holzforschung. 2011;65:673-9.

40. Liers C, Arnstadt T, Ullrich R, Hofrichter M. Patterns of lignin degradation and oxidative enzyme secretion by different wood- and litter-colonizing basidiomycetes and ascomycetes grown on beech-wood. FEMS Microbiol Ecol. 2011;78:91-102.

41. McKinney EC, Ali N, Traut A, Feldmann KA, Belostotsky DA, McDowell JM, et al. Sequence-based identification of T-DNA insertion mutations in Arabidopsis: actin mutants act2-1 and act4-1. Plant J. 1995;8:613-22.

42. Porebski S, Bailey LG, Baum BR. 1997. Modification of a CTAB DNA extraction protocol for plants containing high polysaccharide and polyphenol components. Plant Mol Biol Report. 1997;15:8-15.

43. Ewing B, Hillier L, Wendl MC, Green P. Base-calling of automated sequencer traces using phred. I. Accuracy assessment. Genome Res. 1998;8:175-85.

44. Joshi NA, Fass JN: Sickle: A sliding-window, adaptive, quality-based trimming tool for FastQ files (Version 1.33) [Software]. https://github.com/najoshi/sickle; 2011. Accessed 22 Aug 2017.

45. Hackl T, Hedrich R, Schultz J, Förster F. Proovread: large-scale high-accuracy PacBio correction through iterative short read consensus. Bioinformatics. 2014;30:3004-11.

46. Koren S, Walenz BP, Berlin K, Miller JR, Bergman NH, Phillippy AM. Canu: scalable and accurate long-read assembly via adaptive k-mer weighting and repeat separation. Genome Res. 2017; https://doi.org/10.1101/gr.215087.116.

47. Boetzer M, Henkel CV, Jansen HJ, Butler D, Pirovano W. Scaffolding preassembled contigs using SSPACE. Bioinformatics. 2011;27:578-9.

48. Boetzer M, Pirovano W. SSPACE-LongRead: scaffolding bacterial draft genomes using long read sequence information. BMC Bioinformatics. 2014;15:211.

49. Li H, Ruan J, Durbin R. Mapping short DNA sequencing reads and calling variants using mapping quality scores. Genome Res. 2008;18:1851-8.

50. Parra G, Bradnam K, Korf ICEGMA. A pipeline to accurately annotate core genes in eukaryotic genomes. Bioinformatics. 2007;23:1061-7.

51. Chaisson MJ, Tesler G. Mapping single molecule sequencing reads using basic local alignment with successive refinement (BLASR): application and theory. BMC Bioinformatics. 2012;13:238.

52. Li H, Handsaker B, Wysoker A, Fennell T, Ruan J, Homer N, et al. The sequence alignment/map format and SAMtools. Bioinformatics. 2009;25:2078-9.

53. Trapnell C, Pachter L, Salzberg SL. TopHat: discovering splice junctions with RNA-Seq. Bioinformatics. 2009;25:1105-11.

54. Haas BJ, Papanicolaou A, Yassour M, Grabherr M, Blood PD, Bowden J, et al. De novo transcript sequence reconstruction from RNA-seq using the trinity platform for reference generation and analysis. Nat Protoc. 2013:8:1494-512.

55. Besemer J, Borodovsky M. Heuristic approach to deriving models for gene finding. Nucleic Acids Res. 1999;27:3911-20.

56. Besemer J, Lomsadze A, Borodovsky M. GeneMarkS: a self-training method for prediction of gene starts in microbial genomes. Implications for finding sequence motifs in regulatory regions. Nucleic Acids Res. 2001;29:2607-18.

57. Borodovsky M, Lomsadze A, Ivanov N, Mills R. Eukaryotic gene prediction using GeneMark.Hmm. Curr Protoc Bioinformatics. 2003; https://doi.org/10. 1002/0471250953.bi0406s01.

58. Borodovsky M, Lomsadze A. Eukaryotic gene prediction using GeneMark. Hmm-E and GeneMark-ES. Curr Protoc bioinformatics. 2011. 2011; https:// doi.org/10.1002/0471250953.bi0406s35.

59. Haas BJ, Delcher AL, Mount SM, Wortman JR, Smith RK Jr, Hannick LI, et al. Improving the Arabidopsis genome annotation using maximal transcript alignment assemblies. Nucleic Acids Res. 2003;31:5654-66.

60. Stanke M, Morgenstern BAUGUSTUS. A web server for gene prediction in eukaryotes that allows user-defined constraints. Nucleic Acids Res. 2005;33: W465-7.

61. Kent WJ. BLAT-the BLAST-like alignment tool. Genome Res. 2002;12:656-4

62. Wu TD, Watanabe CK. GMAP: a genomic mapping and alignment program for mRNA and EST sequences. Bioinformatics. 2005;21:1859-75.

63. Haas BJ, Salzberg SL, Zhu W, Pertea M, Allen JE, Orvis J, et al. Automated eukaryotic gene structure annotation using EVidenceModeler and the program to assemble spliced alignments. Genome Biol. 2008;9:R7.

64. Trapnell C, Williams BA, Pertea G, Mortazavi A, Kwan G, van Baren MJ, et al. Transcript assembly and quantification by RNA-Seq reveals unannotated transcripts and isoform switching during cell differentiation. Nat Biotechnol. 2010;28:511-5.

65. Trapnell C, Roberts A, Goff L, Pertea G, Kim D, Kelley DR, et al. Differential gene and transcript expression analysis of RNA-seq experiments with TopHat and cufflinks. Nat Protoc. 2012;7:562-78.

66. Altschul SF, Gish W, Miller W, Myers EW, Lipman DJ. Basic local alignment search tool. J Mol Biol. 1990;215:403-10.

67. Zdobnov EM, Apweiler R. InterProScan-an integration platform for the signature-recognition methods in InterPro. Bioinformatics. 2001;17:847-8. 
68. Jones P, Binns D, Chang HY, Fraser M, Li W, McAnulla C, et al. InterProScan 5: genome-scale protein function classification. Bioinformatics. 2014;30: $1236-40$.

69. Conesa A, Götz S, Garcia-Gomez JM, Terol J, Talon M, Robles M. Blast2GO: a universal tool for annotation, visualization and analysis in functional genomics research. Bioinformatics. 2005:21:3674-6.

70. Conesa A, Götz S. Blast2GO: a comprehensive suite for functional analysis in plant genomics. Int J Plant Genomics. 2008;2008:619832.

71. Marchler-Bauer A, Bryant SH. CD-search: protein domain annotations on the fly. Nucleic Acids Res. 2004;32:W327-31.

72. Marchler-Bauer A, Anderson JB, Chitsaz F, Derbyshire MK, DeWeese-Scott C, Fong $\mathrm{JH}$, et al. CDD: specific functional annotation with the conserved domain database. Nucleic Acids Res. 2009;37:D205-10.

73. Marchler-Bauer A, Lu S, Anderson JB, Chitsaz F, Derbyshire MK, DeWeese-Scott C, et al. CDD: a conserved domain database for the functional annotation of proteins. Nucleic Acids Res. 2011;39:D225-9.

74. Marchler-Bauer A, Zheng C, Chitsaz F, Derbyshire MK, Geer LY, Geer RC, et al, CDD: conserved domains and protein three-dimensional structure. Nucleic Acids Res. 2013;41:D348-52

75. Marchler-Bauer A, Derbyshire MK, Gonzales NR, Lu S, Chitsaz F, Geer LY, et al. CDD: NCBI's conserved domain database. Nucleic Acids Res. 2015;43:D222-6.

76. Yin Y, Mao X, Yang J, Chen X, Mao F, dbCAN XY. A web resource for automated carbohydrate-active enzyme annotation. Nucleic Acids Res. 2012;40:W445-51.

77. Skinner ME, Uzilov AV, Stein LD, Mungall CJ, Holmes IH. JBrowse: a nextgeneration genome browser. Genome Res. 2009;19:1630-8.

78. Skinner ME, Holmes $1 \mathrm{H}$. Setting up the JBrowse genome browser. Curr Protoc Bioinformatics. 2010, 2010; https://doi.org/10.1002/0471250953. bi0913s32.

79. Sirand-Pugnet $P$, Labarère J. Molecular characterization of the Pri3 gene encoding a cysteine-rich protein, specifically expressed during fruiting initiation within the Agrocybe aegerita complex. Curr Genet. 2002;41:31-42.

80. Hofrichter M, Ullrich R, Pecyna MJ, Liers C, Lundell T. New and classic families of secreted heme peroxidases. Appl Microbiol Biotechnol. 2010;87:871-97.

81. Benen JA, Sánchez-Torres P, Wagemaker MJ, Fraaije MW, van Berkel WJ, Visser J. Molecular cloning, sequencing, and heterologous expression of the vaoA gene from Penicillium simplicissimum CBS 170.90 encoding vanillylalcohol oxidase. J Biol Chem. 1998;273:7865-72.

82. van den Heuvel RH, van den Berg WA, Rovida S, van Berkel WJ. Laboratoryevolved vanillyl-alcohol oxidase produces natural vanillin. J Biol Chem. 2004; 279:33492-500

83. Matsumura H, Umezawa K, Takeda K, Sugimoto N, Ishida T, Samejima M, et al. Discovery of a eukaryotic pyrroloquinoline quinone-dependent oxidoreductase belonging to a new auxiliary activity family in the database of carbohydrateactive enzymes. PLoS One. 2014:9:e104851.

84. Li X, Beeson WT 4th, Phillips CM, Marletta MA, Cate JHD. Structural basis for substrate targeting and catalysis by fungal polysaccharide monooxygenases. Structure. 2012;20:1051-61.

85. Morin E, Kohler A, Baker AR, Foulongne-Oriol M, Lombard V, Nagy LG, et al. Genome sequence of the button mushroom Agaricus bisporus reveals mechanisms governing adaptation to a humic-rich ecological niche. Proc Natl Acad Sci U S A. 2012:109:17501-6.

86. Larraya LM, Pérez G, Ritter E, Pisabarro AG, Ramírez L. Genetic linkage map of the edible basidiomycete Pleurotus ostreatus. Appl Environ Microbiol. 2000;66:5290-300.

87. Martin F, Aerts A, Ahrén D, Brun A, Danchin EGJ, Duchaussoy F, et al. (2008) the genome of Laccaria bicolor provides insights into mycorrhizal symbiosis. Nature. 2008;452:88-92.

88. Murata Y, Fujii M, Zolan ME, Kamada T. Molecular analysis of pcc1, a gene that leads to A-regulated sexual morphogenesis in Coprinus cinereus. Genetics. 1998;149:1753-61.

89. Liu Y, Srivilai $P$, Loos S, Aebi M, Kües U. An essential gene for fruiting body initiation in the basidiomycete Coprinopsis cinerea is homologous to bacterial cyclopropane fatty acid synthase genes. Genetics. 2006;172:873-84.

90. Muraguchi $\mathrm{H}$, Kamada T. The ich1 gene of the mushroom Coprinus cinereus is essential for pileus formation in fruiting. Development. 1998;125:3133-41.

91. Terashima K, Yuki K, Muraguchi H, Akiyama M, Kamada T. The dst1 gene involved in mushroom photomorphogenesis of Coprinus cinereus encodes a putative photoreceptor for blue light. Genetics. 2005;171:101-8.

92. Kuratani M, Tanaka K, Terashima K, Muraguchi H, Nakazawa T, Nakahori K, et al. The dst2 gene essential for photomorphogenesis of Coprinopsis cinerea encodes a protein with a putative FAD-binding-4 domain. Fungal Genet Biol. 2010:47:152-8.

93. Fernandez Espinar MT, Labarère J. Cloning and sequencing of the aa-Pri1 gene specifically expressed during fruiting initiation in the edible mushroom Agrocybe aegerita, and analysis of the predicted amino-acid sequence. Curr Genet. 1997:32:420-4.

94. Santos C, Labarère J. Aa-Pri2, a single-copy gene from Agrocybe aegerita, specifically expressed during fruiting initiation, encodes a hydrophobin with a leucine-zipper domain. Curr Genet. 1999;35:564-70.

95. Berne S, Križaj I, Pohleven F, Turk T, Maček P, Sepčić K. Pleurotus and Agrocybe hemolysins, new proteins hypothetically involved in fungal fruiting. Biochim Biophys Acta. 2002;1570:153-9.

96. Berne S, Sepcić K, Anderluh G, Turk T, Macek P, Poklar Ulrih N. Effect of pH on the pore forming activity and conformational stability of ostreolysin, a lipid raft-binding protein from the edible mushroom Pleurotus ostreatus. Biochemistry. 2005;44:11137-47.

97. Berne S, Pohleven J, Vidic I, Rebolj K, Pohleven F, Turk T, et al. Ostreolysin enhances fruiting initiation in the oyster mushroom (Pleurotus ostreatus). Mycol Res. 2007;111:1431-6.

98. Muraguchi H, Fujita T, Kishibe Y, Konno K, Ueda N, Nakahori K, et al. The exp1 gene essential for pileus expansion and autolysis of the inky cap mushroom Coprinopsis cinerea (Coprinus cinereus) encodes an HMG protein. Fungal Genet Biol. 2008;45:890-6

99. Arima T, Yamamoto M, Hirata A, Kawano S, Kamada T. The eln3 gene involved in fruiting body morphogenesis of Coprinus cinereus encodes a putative membrane protein with a general glycosyltransferase domain. Fungal Genet Biol. 2004;41:805-12.

100. Muraguchi $\mathrm{H}$, Kamada TA. Mutation in the eln2 gene encoding a cytochrome P450 of Coprinus cinereus affects mushroom morphogenesis. Fungal Genet Biol. 2000;29:49-59.

101. Pecyna MJ, Ullrich R, Bittner B, Clemens A, Scheibner K, Schubert R, et al. Molecular characterization of aromatic peroxygenase from Agrocybe aegerita. Appl Microbiol Biotechnol. 2009;84:885-97.

102. Riley R, Salamov AA, Brown DW, Nagy LG, Floudas D, Held BW, et al. Extensive sampling of basidiomycete genomes demonstrates inadequacy of the whiterot/brown-rot paradigm for wood decay fungi. Proc Natl Acad Sci. 2014;111: 9923-8.

103. Kües U, Rühl M. Multiple multi-copper oxidase gene families in basidiomycetes - what for? Curr Genomics. 2011;12:72-94.

104. Levasseur A, Lomascolo A, Chabrol O, Ruiz-Dueñas FJ, Boukhris-Uzan E, Piumi F, et al. The genome of the white-rot fungus Pycnoporus cinnabarinus: a basidiomycete model with a versatile arsenal for lignocellulosic biomass breakdown. BMC Genomics. 2014;15:486.

105. Choo JH, Hong CP, Lim JY, Seo JA, Kim YS, Lee DW, et al. Whole-genome de novo sequencing, combined with RNA-Seq analysis, reveals unique genome and physiological features of the amylolytic yeast Saccharomycopsis fibuligera and its interspecies hybrid. Biotechnol Biofuels. 2016;9:246.

106. Ferreira Filho JA, Horta MAC, Beloti LL, Dos Santos CA, de Souza AP. Carbohydrate-active enzymes in Trichoderma harzianum: a bioinformatic analysis bioprospecting for key enzymes for the biofuels industry. BMC Genomics. 2017;18:779.

107. Idnurm A, Heitman J. Light controls growth and development via a conserved pathway in the fungal kingdom. PLoS Biol. 2005;3:e95.

\section{Submit your next manuscript to BioMed Central and we will help you at every step:}

- We accept pre-submission inquiries

- Our selector tool helps you to find the most relevant journal

- We provide round the clock customer support

- Convenient online submission

- Thorough peer review

- Inclusion in PubMed and all major indexing services

- Maximum visibility for your research

Submit your manuscript at www.biomedcentral.com/submit 